\title{
The efficacy of duloxetine, non-steroidal anti-inflammatory drugs, and opioids in osteoarthritis: a systematic literature review and meta-analysis
}

Julie Myers ${ }^{1 *}$, Ronald C Wielage ${ }^{1}$, Baoguang Han ${ }^{2}$, Karen Price ${ }^{2}$, James Gahn ${ }^{1}$, Marie-Ange Paget ${ }^{3}$ and Michael Happich ${ }^{4}$

\begin{abstract}
Background: This meta-analysis assessed the efficacy of duloxetine versus other oral treatments used after failure of acetaminophen for management of patients with osteoarthritis.

Methods: A systematic literature review of English language articles was performed in PUBMED, EMBASE, MedLine In-Process, Cochrane Library, and ClinicalTrials.gov between January 1985 and March 2013. Randomized controlled trials of duloxetine and all oral non-steroidal anti-inflammatory drugs and opioids were included if treatment was $\geq 12$ weeks and the Western Ontario and McMaster Universities Index (WOMAC) total score was available. Studies were assessed for quality using the assessment tool from the National Institute for Health and Clinical Excellence guidelines for single technology appraisal submissions.

WOMAC baseline and change from baseline total scores were extracted and standardized. A frequentist meta-analysis, meta-regression, and indirect comparison were performed using the DerSimonian-Laird and Bucher methods. Bayesian analyses with and without adjustment for study-level covariates were performed using noninformative priors.
\end{abstract}

Results: Thirty-two publications reported 34 trials (2 publications each reported 2 trials) that met inclusion criteria. The analyses found all treatments except oxycodone (frequentist) and hydromorphone (frequentist and Bayesian) to be more effective than placebo. Indirect comparisons to duloxetine found no significant differences for most of the compounds. Some analyses showed evidence of a difference with duloxetine for etoricoxib (better), tramadol and oxycodone (worse), but without consistent results between analyses. Forest plots revealed positive trends in overall efficacy improvement with baseline scores. Adjusting for baseline, the probability duloxetine is superior to other treatments ranges between 15\% to $100 \%$.

Limitations of this study include the low number of studies included in the analyses, the inclusion of only English language publications, and possible ecological fallacy associated with patient level characteristics.

Conclusions: This analysis suggests no difference between duloxetine and other post-first line oral treatments for osteoarthritis $(\mathrm{OA})$ in total WOMAC score after approximately 12 weeks of treatment. Significant results for 3 compounds ( 1 better and 2 worse) were not consistent across performed analyses.

Keywords: Duloxetine, Osteoarthritis, Meta-analysis, NSAID, Opioid, WOMAC

\footnotetext{
* Correspondence: jam@mdm-inc.com

${ }^{1}$ Medical Decision Modeling, Inc, 8909 Purdue Road, Suite 550, Indianapolis, IN, USA

Full list of author information is available at the end of the article
}

\section{Biomed Central}

(c) 2014 Myers et al.; licensee BioMed Central Ltd. This is an Open Access article distributed under the terms of the Creative Commons Attribution License (http://creativecommons.org/licenses/by/2.0), which permits unrestricted use, distribution, and reproduction in any medium, provided the original work is properly credited. The Creative Commons Public Domain Dedication waiver (http://creativecommons.org/publicdomain/zero/1.0/) applies to the data made available in this article, unless otherwise stated. 


\section{Background}

Over 50 treatment modalities for osteoarthritis (OA) of the hip and knee have been evaluated by the Osteoarthritis Research Society International (OARSI) [1,2]. Oral pharmacologic modalities included acetaminophen, non-steroidal anti-inflammatory drugs (NSAIDs), and both strong and weak opioids. Guidelines have recommended acetaminophen for first-line use, with NSAIDs and opioids as second and third lines of treatment [1,3-5]. However, reservations have been expressed concerning the long-term safety and efficacy of NSAIDs and opioids $[1,2,5,6]$. Some reviews have gone further and recommended against their long-term use $[7,8]$. Recently published meta-analyses suggest that currently available oral treatments have only limited efficacy in the average patient with OA [6]. In addition, the efficacy seen in trials seems to be impacted by trial design and baseline factors and may be limited to the first few weeks of use [6].

Earlier meta-analyses have primarily focused on pain and have not assessed broader functioning. They have predominantly investigated single-substance classes, included both short- and long-term trials, and sometimes encompassed both $\mathrm{OA}$ and other chronic pain indications [7-25]. Also, these analyses could not include evidence for substances that were unavailable when they were performed, such as duloxetine, a newly available treatment option in the US.

Duloxetine is a selective serotonin and norepinephrine reuptake inhibitor (SNRI) that has demonstrated efficacy in OA in Phase III clinical trials as well as a favorable adverse event profile across indications [26-28]. Duloxetine is thought to inhibit pain through its enhancement of serotonergic and noradrenergic activity in the central nervous system. It is currently indicated in the US for the management of pain disorders, including diabetic peripheral neuropathic pain (DPNP), fibromyalgia, and chronic musculoskeletal pain due to $\mathrm{OA}$ and chronic low back pain [29].

We conducted a systematic literature review followed by a meta-analysis to assess the efficacy of duloxetine versus other commonly used post first-line OA treatments, including NSAIDs and opioids. Our study reflected the chronic nature of OA by including only trials of 12 or more weeks duration (the recommended duration for confirmatory trials) [30] and a more inclusive set of OA symptoms by using the Western Ontario MacMaster Universities Osteoarthritis Index (WOMAC), which includes subscales for function and stiffness as well as pain [31]. We also sought to confirm the influence of design and baseline factors observed in a recent OA meta-analysis [6]. Both frequentist and Bayesian analyses were undertaken to assess the effect of duloxetine compared to the other available oral treatments.

\section{Methods}

Inclusion and exclusion criteria

Randomized controlled trials (RCTs) were included for OA treatment with duloxetine, NSAIDs or opioids at dosages consistent with United Kingdom prescribing information [32]. All included studies were of at least 12 weeks duration and published in English. Articles were included if they evaluated clinical efficacy using WOMAC total scores. Studies were excluded that did not report clinical efficacy of OA, and did not have at least 2 arms of a treatment of interest, or $1 \mathrm{arm}$ of a treatment of interest and a placebo arm.

When it was unclear from the title or abstract whether a study met the criteria, the full paper was acquired and read. Determination of inclusion/exclusion was performed by 2 persons working independently. When their conclusions were not in agreement the persons met and came to a consensus.

\section{Literature search}

The literature search was performed on all articles published between January 1985 and March 2013 in PUBMED, EMBASE, MEDLINE In-Process \& Other Non-Indexed Citations, Cochrane Central Register of Controlled Trials, Cochrane Database of Systematic Reviews, and ClinicalTrials.gov. The search conducted in PUBMED used the following terms: (ibuprofen OR naproxen OR diclofenac OR meloxicam OR etoricoxib OR celecoxib OR mefenamic OR indometacin OR etodolac OR tramadol OR morphine OR codeine OR dihydrocodeine OR oxycodone OR diamorphine OR methadone OR hydromorphone OR duloxetine) AND (osteoarthritis) AND (English [lang]) AND (clinical trial [ptyp]). The search conducted in the other databases used the same search terms, but without the specific limitation of clinical trial publication type.

\section{Data extraction}

Data extraction was performed by 1 reviewer and checked by a second reviewer using a predefined data extraction form. Discrepancies were resolved by discussion between reviewers. For each study, reviewers extracted data that were deemed to potentially impact efficacy outcomes, such as study population (percent women, mean age, mean duration of $\mathrm{OA}$ ), study design (duration, washout period, flare requirement, concomitant analgesic use, enriched enrollment, missing imputation technique), and outcomes (WOMAC score at baseline, endpoint, and change from baseline with measures of variance). Studies were categorized as having a washout period if the publication mentioned a period of washout or no treatment before randomization. A study was classified as requiring flare if the publication stated that after the washout/no treatment period patients were required 
to exhibit a flare of symptoms to continue in the study. Studies were classified as allowing concomitant analgesic use if patients could use analgesic medications in addition to their assigned treatment throughout the study; rescue medication was not considered concomitant use.

For studies that did not report sufficient data to be included in the analysis, 3 attempts were made to contact authors by email to obtain missing information. Studies were assessed for quality using the assessment tool from the National Institute for Health and Clinical Excellence (NICE) guidelines for Single Technology Appraisal submissions [33]. This 7-item questionnaire evaluates each trial based on randomization, adequate concealment of treatment allocation, similarities between treatment groups, degree of blinding, balance of withdrawals and dropouts between treatment groups, reporting of all outcomes measured, and use of intention to treat analyses. Studies were assessed by one reviewer and independently checked by a second reviewer. Positive responses were tallied for a total possible score of 7 , with higher scores representing better quality.

\section{Outcome measure}

The outcome measure for the meta-analysis was the change from baseline total WOMAC score as reported at 12 or more weeks. The WOMAC instrument consists of 24 questions answered on a $0-4$ Likert or $0-100$ visual analogue scale (VAS). The WOMAC has 3 subscales: function (17 questions), pain (5 questions), and stiffness (2 questions). A lower WOMAC score indicates fewer symptoms, thus improvement is shown as a negative value; negative values of larger magnitude are indicative of greater efficacy. WOMAC total and subscale scores are reported inconsistently, with publications reporting scores on different scales, some subscale scores and not others, different measures of variance, or no measures of

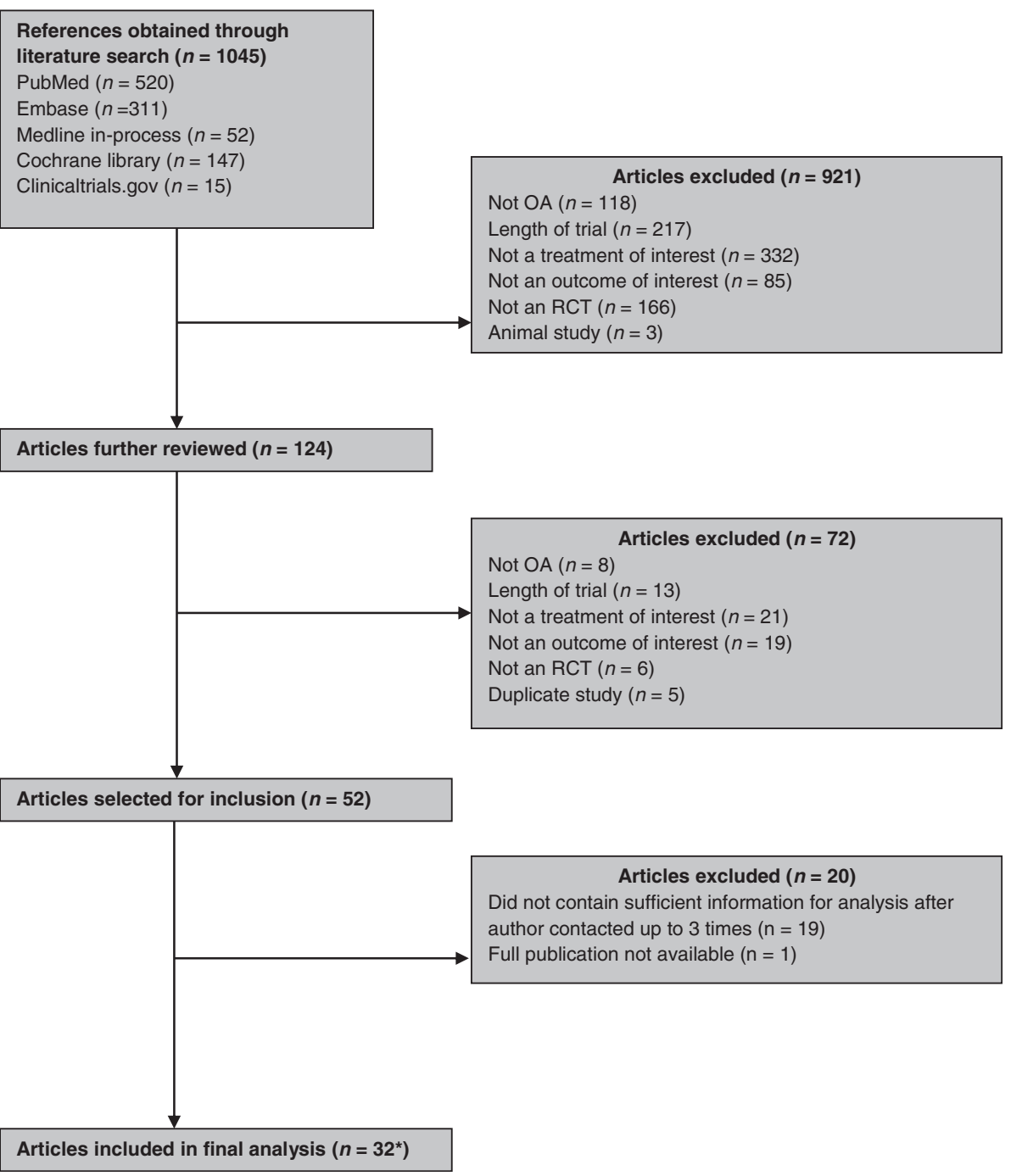

Figure 1 Article selection flow chart. *Reporting 34 studies. 
Table 1 Characteristics of all included studies (Alphabetically ordered)

\begin{tabular}{|c|c|c|c|c|c|c|c|c|c|c|}
\hline Study & Treatment & $\mathrm{n}$ & Mean age (yrs) & $\begin{array}{l}\text { Baseline } \\
\text { WOMAC } \\
\text { score (SD) }\end{array}$ & $\begin{array}{l}\text { Change from } \\
\text { baseline WOMAC } \\
\text { score (SD) }\end{array}$ & $\begin{array}{l}\text { Percentage } \\
\text { women }\end{array}$ & $\begin{array}{c}\text { Duration } \\
\text { OA at } \\
\text { baseline (yrs) }\end{array}$ & $\begin{array}{l}\text { Flare } \\
\text { required }\end{array}$ & $\begin{array}{l}\text { Concomitant } \\
\text { analgesic } \\
\text { allowed }^{\mathrm{d}}\end{array}$ & OA site \\
\hline \multirow[t]{2}{*}{ Abou-Raya et al. 2012 [49] } & Duloxetine & 144 & 68.9 & $50.63(9.56)$ & $-12.40(14.02)$ & 16 & 5.7 & No & Yes & Knee \\
\hline & Placebo & 144 & 68.5 & $50.94(9.47)$ & $-3.96(15.24)$ & 17 & 5.6 & & & \\
\hline Afilalo et al. 2010 [50] $]^{f}$ & Oxycodone 40-100 mg & 342 & 58.2 & & $-27.50(21.75)$ & 59 & & No & Not mentioned & Knee \\
\hline Study NCT00421928 & Placebo & 337 & 58.2 & & $-22.50(21.00)$ & 59 & & & & \\
\hline \multirow[t]{2}{*}{ Baerwald et al. $2010[51]^{\mathrm{b}}$} & Naproxen 1000 mg & 156 & 62.26 & & $-22.54(20.40)$ & 32.1 & & Yes & No & Hip \\
\hline & Placebo & 331 & 63.29 & & $-14.80(22.27)$ & 37.2 & & & & \\
\hline \multirow[t]{3}{*}{ Bensen et al. 1999 [52] } & Celecoxib 200 mg & 202 & 63 & $53.13(17.08)$ & $-12.50(18.06)$ & 72 & 9 & No & No & Knee \\
\hline & Naproxen 1000 mg & 198 & 62 & $55.10(14.58)$ & $-12.40(18.91)$ & 71 & 10 & & & \\
\hline & Placebo & 203 & 62 & $53.85(15.42)$ & $-6.35(16.18)$ & 75 & 11 & & & \\
\hline \multirow[t]{3}{*}{ Bingham et al. 2007a [53] } & Etoricoxib $30 \mathrm{mg}$ & 231 & 62.1 & $65.40(13.03)$ & $-24.37(21.37)$ & 66.2 & & Yes & No & Hip/knee \\
\hline & Celecoxib $200 \mathrm{mg}$ & 241 & 62.5 & $66.20(13.24)$ & $-22.21(21.66)^{\mathrm{a}}$ & 69.7 & & & & \\
\hline & Placebo & 127 & 62.8 & $64.67(13.30)$ & $-10.98(22.14)^{\mathrm{a}}$ & 65.4 & & & & \\
\hline \multirow[t]{3}{*}{ Bingham et al. 2007b [53] } & Etoricoxib $30 \mathrm{mg}$ & 244 & 61.9 & $67.23(13.24)$ & $-24.37(22.19)$ & 69.7 & & Yes & No & Hip/knee \\
\hline & Celecoxib 200 mg & 247 & 62.2 & $65.59(14.59)$ & $-23.19(23.29)^{a}$ & 61.9 & & & & \\
\hline & Placebo & 117 & 60.9 & $64.98(13.81)$ & $-12.29(22.63)^{\mathrm{a}}$ & 65 & & & & \\
\hline \multirow[t]{2}{*}{ Boswell et al. 2008 [54] } & Celecoxib 200 mg & 185 & 59.7 & $63.55(14.70)$ & $-23.46(24.51)^{\mathrm{a}}$ & 67 & 8.8 & No & No & Knee \\
\hline & Placebo & 186 & 60.5 & $63.37(13.68)$ & $-18.46(23.46)^{a}$ & 73 & 8 & & & \\
\hline Burch et al. $2007[55]^{f}$ & Tramadol 200-300 mg & 432 & 62 & & $34.96(14.74)^{9}$ & 64 & & Yes & No & Knee \\
\hline Study NCT00833794 & Placebo & 214 & 62 & & $35.20(15.13)^{9}$ & 62 & & & & \\
\hline Chappell et al. 2011 [26] & Duloxetine 60-120 mg & 128 & 63.16 & $51.63(10.45)$ & $-20.50(11.87)$ & 70 & 8.14 & No & Yes & Knee \\
\hline Study NCT00433290 & Placebo & 128 & 61.9 & $53.82(9.04)$ & $-16.25(12.26)$ & 84 & 6.74 & & & \\
\hline Chappell et al. 2009 [27] ${ }^{b}$ & Duloxetine 60-120 mg & 111 & 62.07 & $57.10(12.15)$ & $-24.01(16.07)$ & 63.06 & 9.04 & No & Yes & Knee \\
\hline Study NCT00408421 & Placebo & 120 & 62.48 & $56.51(11.12)$ & $-16.81(13.67)$ & 67.5 & 9.3 & & & \\
\hline \multirow[t]{2}{*}{ Clegg et al. $2006[56]^{\mathrm{b}, \mathrm{e}}$} & Celecoxib 200 mg & 318 & 59.4 & $47.10(13.36)$ & $-17.95(14.98)$ & 66.7 & 10.1 & No & Yes & Knee \\
\hline & Placebo & 313 & 58.2 & $46.23(13.49)$ & $-14.58(15.99)$ & 63.9 & 9.5 & & & \\
\hline \multirow[t]{4}{*}{ DeLemos et al. 2011 [57] } & Tramadol $200 \mathrm{mg}$ & 199 & 62 & $61.13(14.02)$ & $-16.24(24.22)$ & 62.3 & 8.5 & No & No & Hip/knee \\
\hline & Tramadol $300 \mathrm{mg}$ & 199 & 59.7 & $60.37(15.93)$ & $-22.10(24.16)$ & 61.8 & 7.6 & & & \\
\hline & Celecoxib 200 mg & 202 & 60 & $58.21(15.26)$ & $-25.60(24.58)$ & 64.9 & 8 & & & \\
\hline & Placebo & 200 & 58.9 & $59.95(15.49)$ & $-17.73(24.28)$ & 68.5 & 7.8 & & & \\
\hline
\end{tabular}


Table 1 Characteristics of all included studies (Alphabetically ordered) (Continued)

\begin{tabular}{|c|c|c|c|c|c|c|c|c|c|c|}
\hline \multirow[t]{2}{*}{$\overline{\text { Essex et al. } 2012[58]^{c}}$} & Celecoxib $200 \mathrm{mg}$ & 296 & 60 & $56.15(15.42)$ & $-23.13(19.71)$ & 64.9 & 7.2 & Yes & No & Knee \\
\hline & Naproxen 1000 mg & 293 & 60.7 & $56.56(15.73)$ & $-23.54(19.61)$ & 67.6 & 8.5 & & & \\
\hline \multirow[t]{3}{*}{ Fishman et al. 2007 [59] } & Tramadol $200 \mathrm{mg}$ & 107 & 61 & $58.42(13.99)$ & $-24.39(21.19)^{\mathrm{a}}$ & 59.8 & & No & Yes & Knee \\
\hline & Tramadol $300 \mathrm{mg}$ & 105 & 60 & $63.74(15.21)$ & $-25.54(44.61)$ & 65.7 & & & & \\
\hline & Placebo & 224 & 61 & $61.29(14.16)$ & $-18.82(38.32)$ & 61.6 & & & & \\
\hline \multirow[t]{2}{*}{ Fleischmann et al. 2006 [60] $]^{\mathrm{b}}$} & Celecoxib $200 \mathrm{mg}$ & 444 & 61.3 & $50.94(16.76)$ & $-16.67(18.95)$ & 67.1 & 6.7 & No & No & Knee \\
\hline & Placebo & 231 & 61.5 & $48.65(16.97)$ & $-9.69(16.82)$ & 66.2 & 6.6 & & & \\
\hline \multirow[t]{2}{*}{ Fleischmann et al. 2001 [61] } & Tramadol 200-400 mg & 63 & 62.52 & & $41.60(20.50)^{g}$ & 65.1 & 7.94 & Yes & No & Knee \\
\hline & Placebo & 66 & 62.45 & & $50.40(22.50)^{9}$ & 59.1 & 7.76 & & & \\
\hline \multirow[t]{3}{*}{ Gana et al. 2006 [36] } & Tramadol 200 mg & 201 & 59.1 & $63.77(13.14)$ & $-21.25(23.92)$ & 63.7 & 7.7 & No & No & Hip/knee \\
\hline & Tramadol 300 mg & 201 & 58.5 & $60.10(14.73)$ & $-20.27(23.81)$ & 59.2 & 8 & & & \\
\hline & Placebo & 205 & 56.4 & $61.82(14.82)$ & $-14.19(23.45)$ & 68.8 & 7.7 & & & \\
\hline \multirow[t]{2}{*}{ Hochberg et al. 2011a [62] } & Celcoxib 200 mg & 242 & 33.2 & & $-5.56(40.51)^{\mathrm{a}, \mathrm{h}}$ & 61.2 & & Yes & Yes & Knee \\
\hline & Placebo & 124 & 32.7 & & & 66.1 & & & & \\
\hline \multirow[t]{2}{*}{ Hochberg et al. 2011b [62] } & Celecoxib $200 \mathrm{mg}$ & 244 & 33 & & $-4.36(41.89)^{\mathrm{a}, \mathrm{h}}$ & 62.7 & & & & Knee \\
\hline & Placebo & 122 & 33 & & & 63.1 & & & & \\
\hline \multirow[t]{2}{*}{ Kivitz et al. 2002 [63] } & Naproxen 1000 mg & 205 & 60.4 & 55.91 & $-18.79(19.78)$ & 63 & 9.4 & No & No & Knee \\
\hline & Placebo & 205 & 60.3 & 55.72 & $-14.04(19.71)$ & 64 & 8.3 & & & \\
\hline \multirow[t]{3}{*}{ Kivitz et al. 2001 [64] } & Celecoxib 200 mg & 207 & 62 & $52.29(16.73)$ & $-10.10(15.92)$ & 65 & 7.2 & Yes & No & Hip \\
\hline & Naproxen 1000 mg & 207 & 64 & $51.88(17.24)$ & $-11.98(16.07)$ & 66 & 7.3 & & & \\
\hline & Placebo & 218 & 64 & $52.81(15.60)$ & $-4.38(15.70)$ & 67 & 7.9 & & & \\
\hline \multirow[t]{2}{*}{ Lehmann et al. $2005[65]^{b}$} & Celecoxib $200 \mathrm{mg}$ & 420 & 62.9 & $52.60(14.93)$ & $-15.31(16.47)$ & 68.3 & 4.4 & Yes & yes & Knee \\
\hline & Placebo & 424 & 61.7 & $51.77(15.09)$ & $-11.77(19.03)$ & 71.9 & 3.9 & & & \\
\hline \multirow[t]{3}{*}{ Leung et al. 2002 [66] } & Etoricoxib $60 \mathrm{mg}$ & 224 & 62.93 & $63.84(13.89)$ & $-22.19(15.91)$ & 77.2 & 5.88 & Yes & No & Hip/knee \\
\hline & Naproxen 1000 mg & 221 & 63.16 & $63.76(13.36)$ & $-21.91(15.81)$ & 78.3 & 6.25 & & & \\
\hline & Placebo & 56 & 64.09 & $68.11(10.83)$ & $-13.26(15.17)$ & 82.1 & 6.3 & & & \\
\hline \multirow[t]{2}{*}{ Markenson et al. $2005[67]^{\mathrm{b}, \mathrm{e}}$} & Oxycodone $10-120 \mathrm{mg}$ & 56 & 62 & $64.70(15.71)^{\mathrm{a}}$ & $-14.93(26.09)$ & 68 & & No & Yes & Hip/knee/spine/other \\
\hline & Placebo & 51 & 64 & $63.80(15.00)$ & $-0.87(19.72)$ & 78 & & & & \\
\hline \multirow[t]{3}{*}{ Puopolo et al. 2007 [68] } & Etoricoxib 30 mg & 224 & 62.1 & 64.95 & $-24.90(23.14)$ & 77.7 & 6.6 & Yes & Yes & Hip/knee \\
\hline & Ibuprofen 2400 mg & 213 & 62.3 & 63.18 & $-21.73(22.49)$ & 73.7 & 6.7 & & & \\
\hline & Placebo & 111 & 64 & 64.56 & $-14.43(21.23)$ & 75.7 & 6.5 & & & \\
\hline
\end{tabular}


Table 1 Characteristics of all included studies (Alphabetically ordered) (Continued)

\begin{tabular}{|c|c|c|c|c|c|c|c|c|c|c|}
\hline \multirow[t]{2}{*}{ Rauck et al. 2013 [69] } & Hydromorphone 16 mg & 330 & 59.5 & & $-17.00(19.98)$ & 64.2 & & No & Yes & Hip/knee \\
\hline & Placebo & 331 & 60 & & $-13.00(20.01)$ & 63 & & & & \\
\hline \multirow[t]{2}{*}{ Schnitzer et al. 2011 [70] } & Celecoxib $200 \mathrm{mg}$ & 419 & 61.7 & $54.90(14.49)$ & $-16.58(15.24)^{a}$ & 61.3 & 3.7 & No & No & Hip \\
\hline & Placebo & 416 & 61.4 & $54.58(15.11)$ & $-10.62(13.83)^{a}$ & 60.6 & 3.8 & & & \\
\hline \multirow[t]{2}{*}{ Schnitzer et al. 2011 [71] ${ }^{\mathrm{b}}$} & Naproxen 1000 mg & 254 & 60 & & $-26.29(18.71)^{a}$ & 70.5 & & Yes & No & Knee \\
\hline & Placebo & 257 & 60.15 & & $-16.04(18.62)^{a}$ & 72.65 & & & & \\
\hline \multirow[t]{2}{*}{ Schnitzer et al. $2010[72]^{b}$} & Naproxen 1000 mg & 227 & 61.1 & $70.08(12.98)$ & $-33.33(20.23)^{a}$ & 67.4 & & Yes & No & Knee \\
\hline & Placebo & 221 & 61 & $69.85(13.12)$ & $-20.42(20.17)^{a}$ & 71.9 & & & & \\
\hline \multirow[t]{2}{*}{ Sheldon et al. 2005 [73] } & Celecoxib $200 \mathrm{mg}$ & 393 & 60.2 & $54.79(15.45)$ & $-16.25(19.08)$ & 63.1 & 6.7 & No & No & Knee \\
\hline & Placebo & 382 & 60.8 & $55.31(14.36)$ & $-9.90(17.01)$ & 61.3 & 7 & & & \\
\hline \multirow[t]{2}{*}{ Sowers et al. $2005[74]^{c}$} & Celecoxib $200 \mathrm{mg}$ & 136 & 61.8 & $46.20(22.16)$ & $-16.30(20.99)$ & 62 & & No & No & Hip/knee \\
\hline & Naproxen 1000 mg & 128 & 63.6 & $51.40(20.36)$ & $-14.70(21.50)$ & 60 & & & & \\
\hline \multirow[t]{2}{*}{ Tannenbaum et al. 2004 [75] } & Celecoxib $200 \mathrm{mg}$ & 481 & 64.1 & $50.73(16.04)$ & $-13.96(16.46)$ & 69.2 & 5.3 & No & No & Knee \\
\hline & Placebo & 243 & 64.6 & $51.25(14.58)$ & $-9.79(16.77)$ & 67.1 & 4.3 & & & \\
\hline \multirow[t]{2}{*}{ Vojtassak et al. 2011 [76] } & Hydromorphone & 138 & 65 & $60.00(10.11)$ & $-17.75(14.62)$ & 77 & & No & Yes & Hip/knee \\
\hline & Placebo & 149 & 66 & $57.92(10.36)$ & $-17.69(15.79)$ & 68 & & & & \\
\hline \multirow[t]{3}{*}{ Wiesenhutter et al. 2005 [77] } & Etoricoxib $30 \mathrm{mg}$ & 214 & 63.1 & $68.68(16.64)$ & $-24.52(22.97)$ & 70.1 & 7.9 & Yes & No & Hip/Knee \\
\hline & Ibuprofen 2400 mg & 210 & 61.3 & $68.13(17.02)$ & $-23.65(23.13)$ & 70 & 8.2 & & & \\
\hline & Placebo & 104 & 59.5 & $69.71(16.52)$ & $-14.20(20.24)$ & 72.1 & 6.9 & & & \\
\hline
\end{tabular}

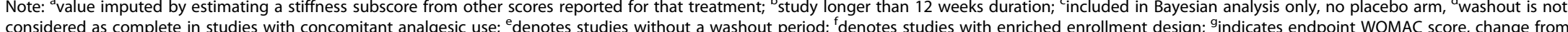
baseline not available in these studies; ${ }^{h}$ indicates difference from placebo in WOMAC score change from baseline. 
variance. Scores are commonly reported as: a) a total of the Likert scores, b) a total of the VAS scores, or c) normalized units with total and subscale scores reported on 0-100 scales [34]. To overcome this issue, WOMAC total scores were converted to a 0-100 normalized scale using a direct ratio. If change from baseline was not reported, it was calculated as the difference between baseline and endpoint or, if not possible, as the difference between baseline and a weighted average of multiple observations during treatment [35]. When subscale scores were reported without the total score, the total score and variance were calculated from the subscales. Missing stiffness subscale scores were imputed by substituting the mean of those reported for that treatment. Studies reporting neither the total score nor the pain and function subscale scores were omitted from the analysis.

\section{Statistical analysis}

Frequentist and Bayesian methods were used to assess the effect of including the direct and indirect data in the analysis. The frequentist meta-analysis using Bucher indirect comparisons was chosen because it reports traditional statistical measures, whereas the Bayesian network meta-analysis allows for inclusion of both direct and indirect information in a single step. In both frequentist and Bayesian methods, if multiple arms for a treatment were present in a study at different doses, the arms used were consistent with the United Kingdom prescribing information. For tramadol, the 400-mg daily dose was not included as it is associated with higher rates of adverse events and similar efficacy to the 300-mg dose [36].

The frequentist meta-analysis used the difference between treatment and placebo of the change from baseline WOMAC score for each active treatment. Random effects models using the DerSimonion-Laird method were employed regardless of heterogeneity due to study design and population dissimilarities [37]. Estimated treatment effects compared to placebo and compared to duloxetine were calculated with their 95\% confidence intervals using the Bucher method of indirect comparison [38-41]. Frequentist analyses were performed with Comprehensive Meta-Analysis software (CMA; Biostat, Englewood NJ) [42]. Publication bias was assessed by funnel plot with Duval and Tweedie's trim and fill [37].

Random effects Bayesian network meta-analyses were performed using the change from baseline score for all available studies. Bayesian methods described in NICE Decision Support Unit documents were modified to accommodate continuous data analysis $[43,44]$. Each trial's specific relative treatment effect was assumed to be drawn from a random effects normal distribution with a common random effects variance for all treatment comparisons. The best model was selected based on the deviance information criteria (DIC), described in Cooper et al. [45] and Dias et al. [46], and standard deviation (SD), which provide measures of model fit. The consistency between direct and indirect evidence was performed using node splitting methods described by Dias et al. [46]. Estimated treatment effects compared to placebo and duloxetine were given with their associated 95\% credible intervals as well as the probability of the treatment being superior to duloxetine. Sensitivity analyses were run on various scenarios, including adjustment for baseline scores, flare requirement, and analgesic use. The Bayesian analyses were conducted using WinBUGS version 1.4.3 (MRC Biostatistics Unit; Cambridge, UK) [47].

Heterogeneity was assessed by calculating the $\mathrm{I}^{2}$ statistic. Twelve population and study characteristics were assessed as possible confounding factors by visually inspecting forest plots for the magnitude and variability of study WOMAC scores. These characteristics included washout period [yes/no], enriched enrollment [yes/no], flare required [yes/no], chronic pain definition $[<6$ months $/>=$ 6 months], baseline pain level, concomitant analgesic use allowed [yes/no], missing imputation technique, quality assessment, study mean age, study mean duration of OA, site of OA, and the percent women. When forest plots suggested a possible relationship, both frequentist and Bayesian meta-regression were conducted to account for heterogeneity of treatment effect. Bayesian methods assumed the same covariate effect for all active treatments. Noninformative priors were used for all parameters; a uniform distribution was used for random effects variance and normal distributions with very large variance for all other parameters, including treatment effect and covariate effect.

\section{Results}

Literature search

Figure 1 provides a flow diagram of the article selection process. Of the initial 1045 articles identified, 124 met the eligibility criteria for possible inclusion based on

\section{Table 2 Study descriptive statistics by treatment}

\begin{tabular}{lcccc}
\hline Treatment & $\begin{array}{c}\text { Total } \\
\mathbf{n}\end{array}$ & $\begin{array}{c}\text { Mean } \\
\text { age (yrs) }\end{array}$ & $\begin{array}{c}\text { Mean percentage } \\
\text { women }\end{array}$ & $\begin{array}{c}\text { Mean duration } \\
\text { of OA (yrs) }\end{array}$ \\
\hline Duloxetine & 383 & 65.00 & 73.25 & 7.48 \\
Ibuprofen & 423 & 61.80 & 71.86 & 7.44 \\
Naproxen & 1889 & 61.73 & 68.41 & $8.26^{\mathrm{a}}$ \\
Celecoxib & 4681 & 61.63 & 65.60 & $6.58^{\mathrm{a}}$ \\
Etoricoxib & 1137 & 62.41 & 72.12 & $6.78^{\mathrm{a}}$ \\
Tramadol & 1507 & 60.60 & 62.67 & $7.95^{\mathrm{a}}$ \\
Oxycodone & 398 & 58.73 & 60.27 & $\mathrm{NR}$ \\
OROS & 468 & $59.5^{\mathrm{b}}$ & 67.97 & $\mathrm{NR}$ \\
hydromorphone & & & & $6.78^{\mathrm{a}}$ \\
\hline Placebo & 6560 & $61.26^{\mathrm{b}}$ & 66.97 & $\mathrm{~N}$ \\
\hline
\end{tabular}

${ }^{a}$ not all studies reported duration of $\mathrm{OA} ;{ }^{b}$ one study did not report mean age; $N R=$ not reported. 
abstract review. Most excluded studies lacked a treatment of interest or the duration was too short. Thirtytwo articles with 47 active treatment arms reported sufficient information to be included in the meta-analysis, for a total number of 17,442 patients (mean age 60.3 years,
$64.9 \%$ women). Sixteen articles were found for celecoxib, 9 for naproxen, 5 each for tramadol and etoricoxib, 3 for duloxetine, and 2 each for ibuprofen, hydromorphone and oxycodone. Of the 20 other studies identified in the literature search, the most frequent reason for exclusion was

Table 3 Quality assessment of included articles

\begin{tabular}{|c|c|c|c|c|c|c|c|c|}
\hline Study & $\begin{array}{l}\text { Randomization } \\
\text { appropriate }^{\mathrm{a}}\end{array}$ & $\begin{array}{c}\text { Treatment } \\
\text { allocation } \\
\text { concealment }^{\text {b }}\end{array}$ & $\begin{array}{l}\text { Groups } \\
\text { similar at } \\
\text { baseline }^{c}\end{array}$ & $\begin{array}{c}\text { Blinding } \\
\text { of all } \\
\text { participants }^{d}\end{array}$ & $\begin{array}{l}\text { Unexpected } \\
\text { imbalance in } \\
\text { drop-outs }^{\mathrm{e}}\end{array}$ & $\begin{array}{l}\text { Measured } \\
\text { outcomes not }^{\text {reported }}\end{array}$ & $\begin{array}{l}\text { ITT analysis, } \\
\text { missing } \\
\text { data }^{9}\end{array}$ & $\begin{array}{l}\text { Quality } \\
\text { score }^{\text {h }}\end{array}$ \\
\hline Abou-Raya et al. 2012 [49] & Yes & Yes & Yes & Yes & No & No & Yes & 7 \\
\hline Afilalo et al. 2010 [50] & Yes & Yes & Yes & Yes & No & No & Yes & 7 \\
\hline Baerwald et al. 2010 [51] & Not clear & Not clear & Yes & Yes & No & No & Yes & 5 \\
\hline Bensen et al. 1999 [52] & Yes & Yes & Yes & Yes & No & No & Yes & 7 \\
\hline Bingham et al. 2007 [53] & Not clear & Not clear & Yes & Yes & No & No & Yes & 5 \\
\hline Boswell et al. 2008 [54] & Not clear & Not clear & Yes & Yes & No & No & Yes & 5 \\
\hline Burch et al. 2007 [55] & Yes & Yes & Yes & Yes & No & No & Not clear & 6 \\
\hline Chappell et al. 2011 [26] & Yes & Yes & Yes & Yes & No & No & Yes & 7 \\
\hline Chappell et al. 2009 [27] & Yes & Yes & Yes & Yes & No & No & Yes & 7 \\
\hline Clegg et al. 2006 [56] & Yes & Yes & Yes & Yes & No & No & Yes & 7 \\
\hline DeLemos et al. 2011 [57] & Not clear & Yes & Yes & Yes & No & No & Yes & 6 \\
\hline Essex et al. 2012 [58] & Yes & Yes & Yes & Yes & No & No & Yes & 7 \\
\hline Fishman et al. 2007 [59] & Yes & Yes & Yes & Yes & Yes, explained & No & Yes & 6 \\
\hline Fleischmann et al. 2006 [60] & Not clear & Yes & Yes & Yes & No & No & Yes & 6 \\
\hline Fleischmann et al. 2001 [61] & Yes & Yes & Yes & Yes & No & No & Yes & 7 \\
\hline Gana et al. 2006 [36] & Yes & Yes & Yes & Yes & No & No & Yes & 7 \\
\hline Hochberg et al. 2011 [62] & Yes & Yes & Yes & Yes & No & No & Yes & 7 \\
\hline Kivitz et al. 2002 [63] & Yes & Yes & Yes & Yes & No & No & Yes & 7 \\
\hline Kivitz et al. 2001 [64] & Yes & Yes & Yes & Yes & No & No & Yes & 7 \\
\hline Lehmann et al. 2005 [65] & Yes & Yes & Yes & Yes & No & No & Yes & 7 \\
\hline Leung et al. 2002 [66] & Yes & Yes & Yes & Yes & No & Yes & Not clear & 5 \\
\hline Markenson et al. 2005 [67] & Yes & Yes & Yes & Yes & No & No & Yes & 7 \\
\hline Puopolo et al. 2007 [68] & Yes & Not clear & Yes & Yes & No & No & Not clear & 5 \\
\hline Rauck et al. 2013 [69] & not clear & Yes & Yes & Yes & No & No & Yes & 6 \\
\hline Schnitzer et al. 2011 [70] & Yes & Yes & Yes & Yes & No & No & Yes & 7 \\
\hline Schnitzer et al. 2011 [71] & Not clear & Not clear & Yes & Yes & No & No & Yes & 5 \\
\hline Schnitzer et al. 2010 [72] & Yes & Not clear & Yes & Yes & No & No & Yes & 6 \\
\hline Sheldon et al. 2005 [73] & Yes & Yes & Yes & Yes & No & No & Yes & 7 \\
\hline Sowers et al. 2005 [74] & Yes & Not clear & Yes & Yes & No & No & Yes & 6 \\
\hline Tannenbaum et al. 2004 [75] & Not clear & Yes & Yes & Yes & No & No & Yes & 6 \\
\hline Vojtassak et al. 2011 [76] & Yes & Yes & Yes & Yes & No & No & Yes & 7 \\
\hline Wiesenhutter et al. 2005 [77] & Not clear & Yes & Yes & Yes & No & No & Yes & 6 \\
\hline
\end{tabular}

a"Was randomisation carried out appropriately?".

"Was the concealment of treatment allocation adequate?".

"'Were the groups similar at the outset of the study in terms of prognostic factors, for example, severity of disease?".

${ }^{\mathrm{d}}$ "Were the care providers, participants and outcome assessors blind to treatment allocation? If any of these people were not blinded, what might be the likely impact on the risk of bias (for each outcome)?".

e"Were there any unexpected imbalances in drop-outs between groups? If so, were they explained or adjusted for?".

"Is there any evidence to suggest that the authors measured more outcomes than they reported?".

" "Did the analysis include an intention-to-treat analysis? If so, was this appropriate and were appropriate methods used to account for missing data?".

"Quality Score is calculated by summing the positive answers to each question ("yes" answers to questions 1-4 and 7, and "no" answers to questions 5 \&6). 
incomplete reporting of WOMAC scores, especially the omission of a measure of variance. One full paper was unavailable [48].

Table 1 presents the studies included in the metaanalysis with 5 extracted study characteristics as well as baseline and change from baseline WOMAC scores. The duration of nearly all studies was 12 to13 weeks, with a range of 12 to 26 weeks. The size of treatment arms ranged from 51 patients in a placebo arm to 481 in a celecoxib arm. Seven studies did not report baseline WOMAC scores. Three studies were identified in which complete WOMAC scores were not reported in the publication, but were available on clinicaltrials.gov. These studies are identified in the table with both the publication reference and the NTC number from clinicaltrials. gov. Table 2 presents descriptive statistics of the included studies grouped by treatment. In Table 3 the quality assessments of the included studies are presented. Of the 32 included articles, 26 (81\%) had a quality score of 6 or 7 (maximum score 7 ) and the other 6 studies had a quality score of 5 , indicating that the included studies were of sufficiently high quality. A funnel plot assessing publication bias, run on all studies as not enough studies per compound were available, was roughly symmetrical, with slightly more studies on the left, indicating little effect of publication bias on the results of this analysis (Figure 2). Missing publications have been imputed using Duval and Tweedie's trim and fill and appear as solid points among the actual publications depicted as circles [37]. This method suggests that possible missing studies would trend to nonsignificant differences in means.

\section{Statistical results}

Results of both the frequentist and Bayesian analyses are shown in Table 4. The frequentist approach analyzed 32 of the 34 studies, excluding Sowers et al. [74] and Essex et al. [58] due to the lack of placebo arms. All active treatments, except hydromorphone and oxycodone, were found to statistically improve the WOMAC total score compared to placebo. Indirect comparisons to duloxetine using the Bucher method found all confidence intervals but etoricoxib encompassed zero, indicating the differences between duloxetine and all treatments except etoricoxib were not statistically significant. Two compounds, ibuprofen and etoricoxib, had an $\mathrm{I}^{2}$ of zero while naproxen, celecoxib, duloxetine, oxycodone, hydromorphone, and tramadol had $\mathrm{I}^{2}$ s of $52 \%, 33 \%, 44 \%, 72 \%, 64 \%$, and $58 \%$, respectively, indicating substantial heterogeneity [78,79]. However, the direction of the treatment effect was the same for all but one study; the magnitude of the treatment effect in these studies was the source of heterogeneity.

The Bayesian network meta-analysis included all 34 studies. Figure 3 depicts the network of direct and indirect evidence. As shown in Table 4, the results lead to similar conclusions as the frequentist results, as all $95 \%$ credible intervals of the difference between duloxetine and active treatments included zero.

To explain heterogeneity/inconsistency, we graphically explored the association of relative effect of the active treatment versus placebo with study-level covariates. Forest plots were generated for each population and study characteristic showing the difference between placebo and treatment of the change from baseline, ordered by the value of the characteristic (see Additional files 1, $2,3,4,5,6,7,8,9,10,11)$. Figure 4 is the forest plot for baseline WOMAC scores. A visual association was indicated between baseline and change from baseline scores, with a higher baseline score associated with a larger negative (improved) change from baseline. Figure 5 is a verifying scatter plot showing the trial-level baseline

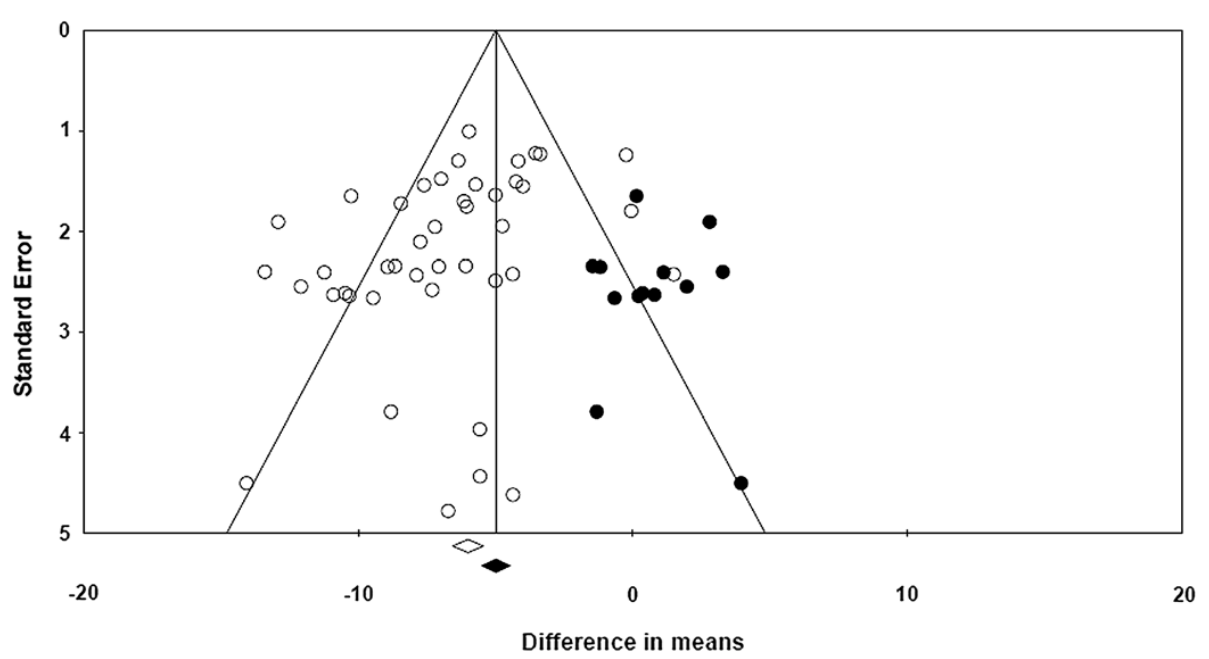

Figure 2 Funnel plot of standard error by difference in mean. Note: o = actual publication; $\bullet=$ hypothetical omitted study. 
Table 4 Indirect comparison: results for WOMAC total score change from baseline

\begin{tabular}{|c|c|c|c|c|c|c|c|c|}
\hline & Duloxetine & Ibuprofen & Naproxen & Celecoxib & Etoricoxib & Tramadol & Oxycodone & Hydromorphone \\
\hline \multicolumn{9}{|l|}{ Frequentist analysis } \\
\hline Number of studies & 3 & 2 & $7^{f}$ & $14^{f}$ & 5 & 5 & 2 & 2 \\
\hline Change from baseline vs. placebo, mean & -6.48 & -8.34 & -8.27 & -5.78 & -11.04 & -3.99 & -8.56 & -2.13 \\
\hline $95 \% \mathrm{Cl}$ & {$[-9.09,-3.88]$} & {$[-11.98,-4.71]$} & {$[-10.27,-6.28]$} & {$[-6.86,-4.69]$} & {$[-13.24,-8.84]$} & {$[-6.74,-1.23]$} & {$[-17.23,0.11]$} & {$[-5.99,1.72]$} \\
\hline $1^{2}(\%)$ & 44.35 & 0 & 51.92 & 32.49 & 0 & 58.03 & 71.99 & 63.54 \\
\hline Indirect vs. Duloxetine ${ }^{a}$ & NA & -1.86 & -1.93 & 0.71 & -4.56 & 2.36 & -2.07 & 4.35 \\
\hline $95 \% \mathrm{Cl}^{\mathrm{b}}$ & NA & {$[-6.33,2.62]$} & {$[-4.70,0.84]$} & {$[-2.12,3.53]$} & {$[-7.97,-1.15]$} & {$[-1.00,5.73]$} & {$[-11.13,6.98]$} & {$[-0.31,9.01]$} \\
\hline \multicolumn{9}{|l|}{ Bayesian analysis } \\
\hline Number of studies contributing to each compound ${ }^{c}$ & 3 & 2 & 9 & 16 & 5 & 5 & 2 & 2 \\
\hline Change from baseline vs. placebo, mean ${ }^{d}$ & -6.47 & -7.85 & -7.9 & -6.2 & -9.53 & -2.89 & -7.04 & -2.19 \\
\hline $95 \% \mathrm{Cl}$ & {$[-9.27,-3.7]$} & {$[-11.59,-4.18]$} & {$[-9.54,-6.27]$} & {$[-7.46,-5.03]$} & {$[-11.86,-7.3]$} & {$[-5.41,-0.54]$} & {$[-11.35,-2.95]$} & {$[-5.52,1.21]$} \\
\hline Indirect vs. Duloxetine ${ }^{a}$ & NA & -1.38 & -1.43 & 0.27 & -3.07 & 3.57 & -0.58 & 4.28 \\
\hline $95 \% \mathrm{Cl}^{\mathrm{b}}$ & NA & {$[-6.04,3.21]$} & {$[-4.65,1.81]$} & {$[-2.78,3.28]$} & {$[-6.66,0.49]$} & {$[-0.17,7.19]$} & {$[-5.69,4.32]$} & {$[-0.01,8.69]$} \\
\hline Probability Duloxetine is Superior & NA & 0.28 & 0.19 & 0.57 & 0.04 & 0.97 & 0.41 & 0.97 \\
\hline $\begin{array}{l}\text { Number of studies contributing to each compound } \\
\text { for adjusted for baseline WOMAC score }\end{array}$ & 3 & 2 & 7 & 14 & 5 & 3 & 1 & 1 \\
\hline Indirect vs. Duloxetine adjusted for baseline WOMAC score ${ }^{e}$ & NA & 1.85 & 0.24 & 0.83 & -0.43 & 4.92 & -4.67 & 8.19 \\
\hline $95 \% \mathrm{Cl}^{\mathrm{b}}$ & NA & {$[-2.13,5.9]$} & {$[-2.36,2.87]$} & {$[-1.45,3.14]$} & {$[-3.4,2.57]$} & {$[1.51,8.34]$} & {$[-13.24,4.07]$} & {$[3.84,12.56]$} \\
\hline Probability Duloxetine is Superior & NA & 0.82 & 0.57 & 0.76 & 0.38 & 1 & 0.15 & 1 \\
\hline
\end{tabular}

${ }^{\mathrm{a} A}$ positive (negative) result indicates that the compared treatment is worse (better) than duloxetine.

bIf zero does not fall between the upper and lower bounds the null hypothesis (treatments are the same) is rejected.

'There are fewer studies in the adjusted analyses.

Random effects model.

'Random effects model adjusting for baseline excluding trials with no baseline.

$\mathrm{f}_{2}$ studies without placebo arms were not included in the frequentist analysis. 


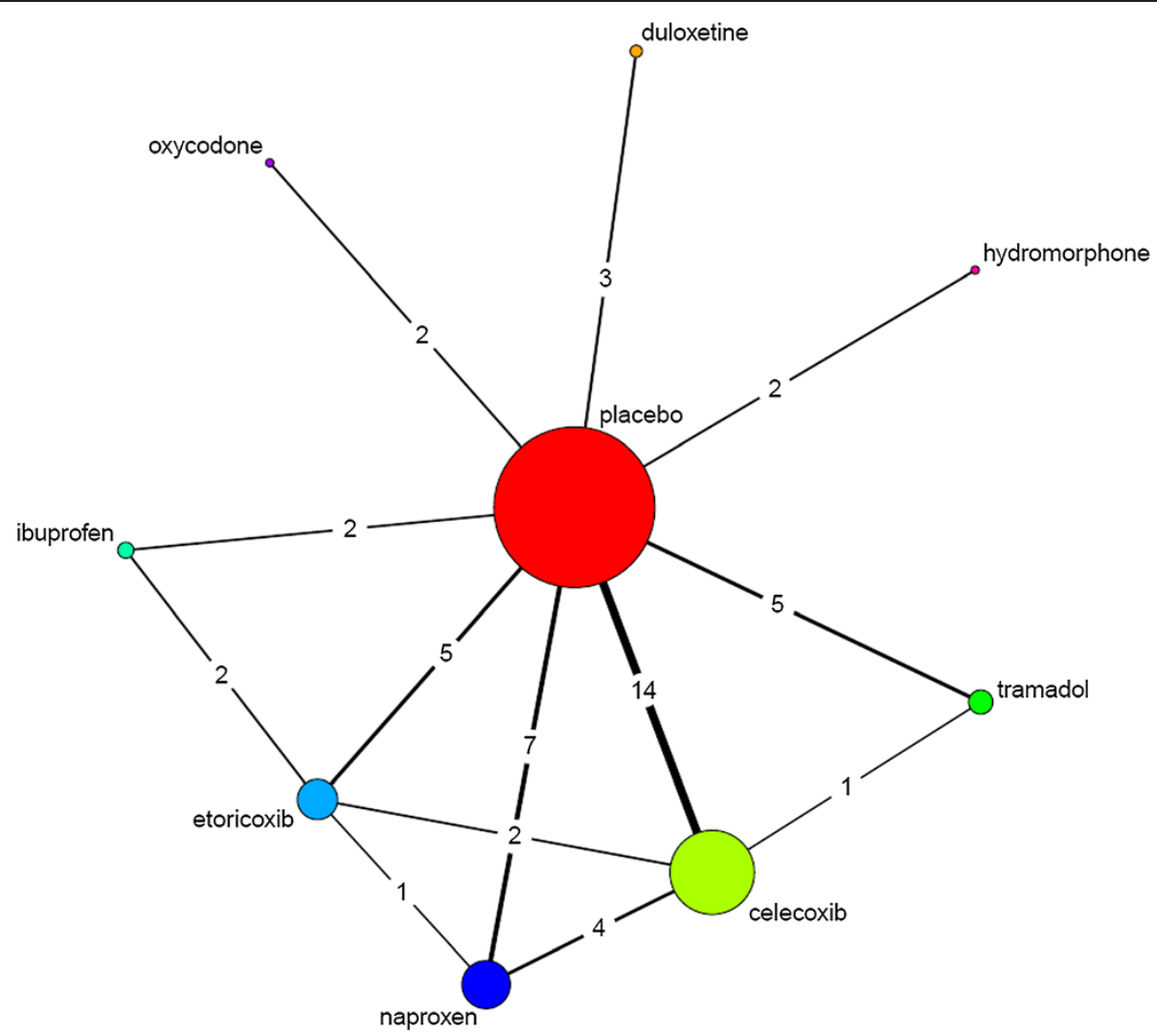

Figure 3 Network of evidence including direct and indirect comparisons. Note: the numbers represent number of comparisons between treatments.

WOMAC scores between 45 and 70 and the relative treatment effect appearing to increase as the trial-level baseline increases. A frequentist meta-regression confirmed an association between the baseline and change from baseline scores $(\mathrm{p}<0.0001)$ with an $\mathrm{R}^{2}$ of 0.573 , indicating much of the observed improvement in symptoms was associated with a higher baseline level of symptoms.

Bayesian meta-regression models including study-level covariates were used to evaluate the extent to which covariates accounted for heterogeneity of treatment effects. Three models including study-level covariates yielded lower, similar DICs. (See Table 5). The model including the baseline score yielded both the lowest DIC and a substantially smaller SD of heterogeneity. Therefore, the model including the baseline score was preferred. Adjusted for baseline score, credible intervals of all treatments but tramadol and hydromorphone included zero, indicating no evidence of difference from duloxetine. In the cases of tramadol and hydromorphone, duloxetine demonstrated evidence of a clear advantage. When adjusted for baseline, the probability of duloxetine being superior increased for naproxen ( $19 \%$ to $57 \%)$, ibuprofen ( $28 \%$ to $82 \%)$, and etoricoxib (4\% to $38 \%$ ), but went down for oxycodone (41\% to $15 \%)$.

\section{Discussion}

Our analysis employed the WOMAC, a common instrument in OA trials, with subscales for function, pain, and stiffness. It is, therefore, a broader measure of OA health than instruments that focus solely on pain. Randomized controlled trials and meta-analyses in OA commonly focus on the difference between the treatment and placebo arms of improvement from baseline to endpoint. Although a commonly reported measure in meta-analysis is the standardized mean difference Cohens $d$, we chose to report the unstandardized total WOMAC score, as it is a more meaningful outcome to clinicians. In the absence of consistent statistical significance, clinical relevance was not discussed. Because OA is a chronic condition, studies were included only with a treatment duration of at least 12 weeks, the current recommended minimum duration of confirmatory chronic pain trials [30]. This has not been universal practice in other meta-analyses of OA [8-11,15-17].

With our choice of the WOMAC composite score as the outcome of interest, we chose a continuous endpoint (mean and standard deviation) rather than a dichotomous variable. It is recognized that others recommend the use of dichotomous variables (eg, $50 \%$ reduction in pain score) for evaluation of chronic pain trials. This recommendation 


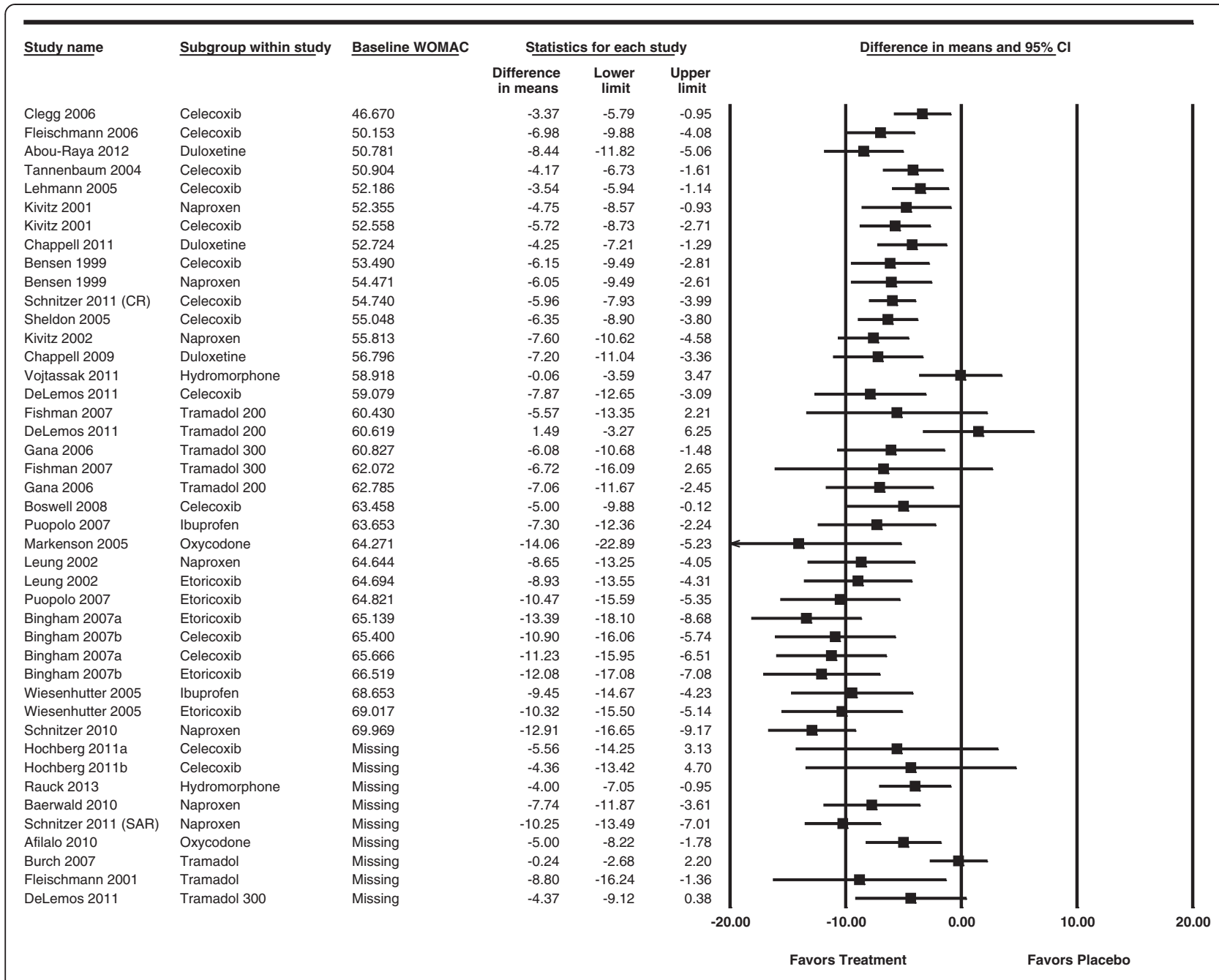

Figure 4 Forest plot by baseline WOMAC showing difference in change from baseline. Note: the lower limit in the Markenson study extends beyond the -20.00 scale of the plot.

is based on the benefits of treatment being frequently unequally distributed, typically presenting as a u-shaped distribution [81]. The WOMAC, however, is rarely reported in this manner, and our aim was to report the broader definition of health that the WOMAC encompasses, rather than pain alone.

Song et al. [41] suggests that judicious use of metaanalytical methodology can come to similar results as direct head-to-head evidence. It is frequently not possible, however, to fully account for differences in patient populations, the impact of different trial designs, and additional hidden confounders. For example, some of the trials applied flexible dose regimens (including 1 duloxetine trial) while others applied fixed dose regimens; this could impact comparative results. Enriched enrollment, a treatment run-in after screening to titrate patients up to optimal tolerability, is frequently used in opioid trials due to their well-known dosing requirements. NSAID trials, on the other hand, tend to exclude patients with a known bleeding risk or cardiovascular risk factors due to NSAIDs' known safety profile. In the case of duloxetine, and in contrast to most other trials, a washout of previous NSAIDs was not enforced. Patients in duloxetine trials were allowed to continue (but not increase) treatment with NSAIDs with a higher proportion of patients receiving NSAIDs in placebo arms. Because this design feature only applied to duloxetine trials, they could not be accounted for overall. Such aspects can limit the interpretation and generalizability of meta-analytic results.

Statistical analyses were performed using both frequentist and Bayesian methods. Frequentist methods have the advantage of using more familiar concepts and terminology. Bayesian network meta-analysis methods have the advantage of using all the data available, such as arms from active treatment controlled trials. In this study both methods produced similar results. 


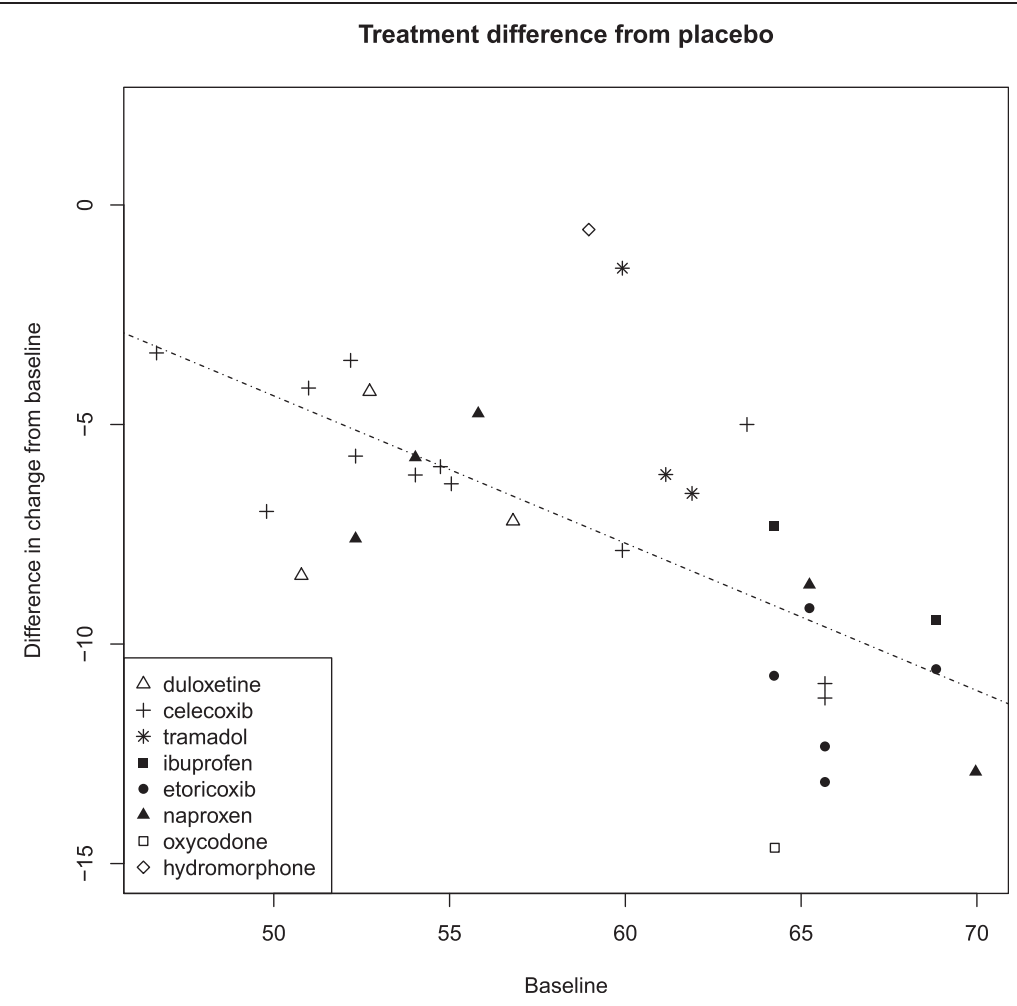

Figure 5 Correlation between baseline WOMAC score and the relative effect of active treatments and placebo.

Our results mirror similar findings from previous studies. A 1997 study could not recommend a choice of NSAID therapy [21]. A more recent meta-analysis commissioned by NICE did not find a statistically significant difference among NSAIDs [82]; guidelines treat NSAIDs as a class differentiated primarily by adverse events [2,3]. A metaanalysis of the short-term efficacy of treatments for OA of the knee found no statistical difference in pain relief between NSAIDs and opioids [6]. For duloxetine, our analysis repeats findings from previous studies in other pain indications. For both DPNP and fibromyalgia, duloxetine has been shown to be of similar efficacy to alternative treatment options $[83,84]$. Our study found a significant

Table 5 Comparison of Bayesian models ${ }^{a}$

\begin{tabular}{lcc}
\hline \multirow{2}{*}{ Model } & \multicolumn{2}{c}{ Random effects } \\
\cline { 2 - 3 } Without adjustment & $\mathbf{1 2 8 . 2 9}$ & Heterogeneity SD \\
Without adjustment excluding & $\mathbf{1 0 7 . 0 0}$ & 1.62 \\
studies with no baseline score & & 1.53 \\
With adjustment & & \\
Baseline & $\mathbf{9 3 . 8 5}$ & 0.59 \\
Flare & $\mathbf{1 0 5 . 3 2}$ & 1.52 \\
Analgesic use & $\mathbf{1 0 5 . 8 8}$ & 1.09 \\
\hline
\end{tabular}

${ }^{\mathrm{a} A}$ lower DIC indicates a better fit of the model. A difference of 3 in the DIC between 2 models is usually meaningful [80]. relationship between baseline symptoms and the magnitude of treatment effect. The related issue of the influence of flare design in trials of NSAIDs has previously been noted $[7,85]$.

A limitation of this meta-analysis was the low number of studies available for analysis. Four or more studies were available for celecoxib, naproxen, tramadol, and etoricoxib. For all other treatments, 3 or fewer studies were found. Eight studies were omitted from the Bayesian adjusted for baseline WOMAC analysis, due to the omission of baseline scores in study publications. These numbers were, however, similar to several other metaanalyses in OA $[7,8,18,21]$. Limiting the literature search to English language publications may have lead to missed RCTs. However, a study examining the effect of an English-language restriction in systematic reviews and meta-analyses found no evidence of bias as a result of the restriction [86]. The funnel plot suggests that publication bias, if any, was towards the exclusion of statistically nonsignificant studies, further supporting our findings of no difference among comparators. Another limitation of this study is the potential for ecological fallacy associated with patient level characteristics. For example, the mean baseline WOMAC score used in the regression analysis could represent a wide variety of patient level baseline scores. A study by Lange et al. [13] points out that imputed data may bias results, showing benefit of treatment where no 
benefit is seen in the non-imputed data. Thus, the imputation methods used in several of the included studies could have introduced bias in the results However, its reported effect size seems to be in the range of alternative opioid treatment options such as tramadol or oxycodone $[50,87]$.

\section{Conclusions}

This meta-analysis found no difference between duloxetine and other post-first line oral treatments for OA in the total WOMAC score after approximately 12 weeks of treatment in a consistent manner. Etoricoxib was more effective than duloxetine in the frequentist analysis and resulted in a $96 \%$ probability of being better than duloxetine in the nonadjusted Bayesian analysis. After adjustment for baseline pain score, however, duloxetine showed evidence of superiority to both tramadol and hydromorphone, but not for the other treatments, including etoricoxib.

\section{Additional files}

Additional file 1: Forest plot by washout showing difference in change from baseline. Note: the lower limit in the Markenson study extends beyond the -20.00 Scale of the plot.

Additional file 2: Forest plot by concomitant analgesics showing difference in change from baseline. Note: the lower limit in the Markenson study extends beyond the -20.00 Scale of the plot.

Additional file 3: Forest plot by flare requirement showing difference in change from baseline. Note: the lower limit in the Markenson study extends beyond the -20.00 Scale of the plot.

Additional file 4: Forest plot by mean age showing difference in change from baseline. Note: the lower limit in the Markenson study extends beyond the -20.00 Scale of the plot

Additional file 5: Forest plot by duration of OA showing difference in change from baseline. Note: the lower limit in the Markenson study extends beyond the -20.00 Scale of the plot.

Additional file 6: Forest plot by site of OA showing difference in change from baseline. Note: the lower limit in the Markenson study extends beyond the -20.00 Scale of the plot.

Additional file 7: Forest plot by percentage women showing difference in change from baseline. Note: the lower limit in the Markenson study extends beyond the -20.00 Scale of the plot.

Additional file 8: Forest plot by enriched enrollment showing difference in change from baseline. Note: the lower limit in the Markenson study extends beyond the -20.00 Scale of the plot.

Additional file 9: Forest plot by chonic pain definition showing difference in change from baseline. Note: the lower limit in the Markenson study extends beyond the -20.00 Scale of the plot.

Additional file 10: Forest plot by missing imputation technique showing difference in change from baseline. Note: the lower limit in the Markenson study extends beyond the -20.00 Scale of the plot.

Additional file 11: Forest plot by quality assessment score showing difference in change from baseline. Note: the lower limit in the Markenson study extends beyond the -20.00 Scale of the plot.

\section{Abbreviations}

DIC: Deviance information criteria; DPNP: Diabetic peripheral neuropathic pain; NICE: National Institute for Health and Clinical Excellence; NSAID: Non-steroidal anti-inflammatory drug; OA: Osteoarthritis; OARSI: Osteoarthritis Research Society International; RCT: Randomized controlled trials; SD: Standard deviation; SNRI: Serotonin and norepinephrine reuptake inhibitor; VAS: Visual analogue scale; WOMAC: Western Ontario and McMaster Universities Index.

\section{Competing interests}

J Myers, R Wielage, and J Gahn are employees of Medical Decision Modeling and were contracted by Eli Lilly and Co. to conduct this study. B Han, K Price, M Paget, and M Happich are employees of Eli Lilly and Co or its subsidiaries.

\section{Authors' contributions}

All authors significantly contributed to the concept and design of the study or data acquisition or analysis or interpretation, and drafting and revising the article. All authors read and approved the final manuscript.

\section{Acknowledgments}

We would like to acknowledge Christopher Bly, Amber Pitts, and Yasir Malik from Medical Decision Modeling Inc. for their contribution to the data and writing review. Funding Source This research was funded by Eli Lilly and Co.

\section{Author details}

${ }^{1}$ Medical Decision Modeling, Inc, 8909 Purdue Road, Suite 550, Indianapolis, IN, USA. ${ }^{2}$ Eli Lilly and Company, Indianapolis, IN, USA. 'illy France, Neuilly sur Seine, France. ${ }^{4}$ Lilly Deutschland $\mathrm{GmbH}$, Bad Homburg, Germany.

Received: 25 September 2013 Accepted: 28 February 2014

Published: 11 March 2014

\section{References}

1. Zhang W, Moskowitz RW, Nuki G, Abramson S, Altman RD, Arden N, Bierma-Zeinstra S, Brandt KD, Croft P, Doherty M, Dougados M, Hochberg M, Hunter DJ, Kwoh K, Lohmander LS, Tugwell P: OARSI recommendations for the management of hip and knee osteoarthritis, Part II: OARSI evidence-based, expert consensus guidelines. Osteoarthr Cartil 2008, 16:137-162.

2. Zhang W, Nuki G, Moskowitz R, Abramson S, Altman RD, Arden N, Bierma-Zeinstra S, Brandt KD, Croft P, Doherty M, Dougados M, Hochberg M, Hunter DJ, Kwoh K, Lohmander LS, Tugwell P: OARSI recommendations for the management of hip and knee osteoarthritis, Part III: changes in evidence following systematic cumulative update of research published through January 2009. Osteoarthr Cartil 2010, 18:476-499.

3. National Collaborating Centre for Chronic Conditions: Osteoarthritis: National Clinical Guideline for Care and Management in Adults. London: Royal College of Physicians; 2008.

4. American Academy of Orthopaedic Surgeons (AAOS): American Academy of Orthopaedic Surgeons Clinical Practice Guideline on the Treatment of Osteoarthritis of the Knee (Non-Arthroplasty). Rosemont: IL; 2008.

5. Zhang W, Doherty M, Arden N, Bannwarth B, Bijlsma J, Gunther K-P, Hauselmann HJ, Herrero-Beaumont G, Jordan K, Kaklamanis P, Leeb B, Lequesne M, Lohmander S, Mazieres B, Martin-Mola E, Pavelka K, Pendleton A, Punzi L, Swoboda B, Varatojo R, Verbruggen G, Zimmermann-Gorska I, Dougados M: EULAR evidence based recommendations for the management of hip osteoarthritis: report of a task force of the EULAR Standing Committee for International Clinical Studies Including Therapeutics (ESCISIT). Ann Rheum Dis 2005, 64:669-681.

6. Bjordal JM, Klovning A, Ljunggren AE, Slørdal L: Short-term efficacy of pharmacotherapeutic interventions in osteoarthritic knee pain: a meta-analysis of randomised placebo-controlled trials. Eur J Pain 2007, 11:125-138.

7. Bjordal JM, Ljunggren AE, Klovning A, Slørdal L: Non-steroidal anti-inflammatory drugs, including cyclo-oxygenase-2 inhibitors, in osteoarthritic knee pain: meta-analysis of randomised placebo controlled trials. BMJ 2004, 329:1317.

8. Nüesch E, Rutjes AW, Husni E, Welch V, Jüni P: Oral or transdermal opioids for osteoarthritis of the knee or hip. Cochrane Database Syst Rev 2009(4). Art No:: CD003115. DOl:10.1002/14651858.CD003115.pub3.

9. Bartels EM, Bliddal H, Schøndorff PK, Altman RD, Zhang W, Christensen R Symptomatic efficacy and safety of diacerein in the treatment of osteoarthritis: a meta-analysis of randomized placebo-controlled trials. Osteoarthr Cartil 2010, 18:289-296.

10. Cepeda MS, Camargo F, Zea C, Valencia L: Tramadol for osteoarthritis. Cochrane Database Syst Rev 2006(3). Art No.: CD005522. DOI: 10.1002/ 14651858.CD005522.pub2. 
11. Garner SE, Fidan DD, Frankish R, Maxwell L: Rofecoxib for osteoarthritis. Cochrane Database Syst Rev 2005(1). Art No.: CD005115. DOl: 10.1002/14651858.CD005115.

12. Berenbaum F, Grifka J, Brown JP, Zacher J, Moore A, Krammer G, Dutta D, Sloan VS: Efficacy of lumiracoxib in osteoarthritis: a review of nine studies. J Int Med Res 2005, 33:21-41.

13. Lange B, Kuperwasser B, Okamoto A, Steup A, Häufel T, Ashworth J, Etropolski M: Efficacy and safety of tapentadol prolonged release for chronic osteoarthritis pain and low back pain. Adv Ther 2010, 27:381-399.

14. Zhang W, Jones A, Doherty M: Does paracetamol (acetaminophen) reduce the pain of osteoarthritis? A meta-analysis of randomised controlled trials. Ann Rheum Dis 2004, 63:901-907.

15. Towheed TE, Maxwell L, Judd MG, Catton M, Hochberg MC, Wells G: Acetaminophen for osteoarthritis. Cochrane Database Syst Rev 2006(1). Art No:: CD004257. DOl: 10.1002/14651858.CD004257.pub2.

16. Porzio F: Meta-analysis of three double-blind comparative trials with sustained-release etodolac in the treatment of osteoarthritis of the knee. Rheumatol Int 1993, 13:19-24.

17. Chen Y-F, Jobanputra P, Barton P, Bryan S, Fry-Smith A, Harris G, Taylor RS: Cyclooxygenase-2 selective non-steroidal anti-inflammatory drugs (etodolac, meloxicam, celecoxib, rofecoxib, etoricoxib, valdecoxib and lumiracoxib) for osteoarthritis and rheumatoid arthritis: a systematic review and economic evaluation. Health Technol Assess 2008, 12:1-278. iii.

18. Avouac J, Gossec L, Dougados M: Efficacy and safety of opioids for osteoarthritis: a meta-analysis of randomized controlled trials. Osteoarthr Cartil 2007, 15:957-965.

19. Lee C, Straus WL, Balshaw R, Barlas S, Vogel S, Schnitzer TJ: A comparison of the efficacy and safety of nonsteroidal antiinflammatory agents versus acetaminophen in the treatment of osteoarthritis: a meta-analysis. Arthritis Care Res 2004, 51:746-754.

20. Riedemann PJ, Bersinic S, Cuddy LJ, Torrance GW, Tugwell PX: A study to determine the efficacy and safety of tenoxicam versus piroxicam, diclofenac and indomethacin in patients with osteoarthritis: a meta-analysis. J Rheumato/ 2095, 1993:20

21. Towheed TE, Hochberg MC: A systematic review of randomized controlled trials of pharmacological therapy in osteoarthritis of the hip. J Rheumatol 1997, 24:349-357.

22. Furlan A, Sandoval J, Mailis-Gagnon A, Tunks E: Opioids for chronic noncancer pain: a meta-analysis of effectiveness and side effects. CMAJ 2006, 174:1589-1594.

23. Mayyas F, Fayers P, Kaasa S, Dale O: A systematic review of oxymorphone in the management of chronic pain. J Pain Symptom Manage 2010, 39:296-308.

24. Noble M, Treadwell JR, Tregear SJ, Coates VH, Wiffen PJ, Akafomo C, Schoelles KM: Long-term opioid management for chronic noncancer pain. Cochrane Database Syst Rev 2010(1). Art No.: CD006605. DOI: 10.1002/ 14651858.CD006605.pub2.

25. Papaleontiou M, Henderson CR Jr, Turner BJ, Moore AA, Olkhovskaya Y, Amanfo L, Reid MC: Outcomes associated with opioid use in the treatment of chronic noncancer pain in older adults: a systematic review and meta-analysis. J Am Geriatr Soc 2010, 58:1353-1369.

26. Chappell AS, Desaiah D, Liu-Seifert H, Zhang S, Skljarevski V, Belenkov Y, Brown JP: A double-blind, randomized, placebo-controlled study of the efficacy and safety of duloxetine for the treatment of chronic pain due to osteoarthritis of the knee. Pain Pract 2011, 11:33-41.

27. Chappell A, Ossanna M, Liu-Seifert H, lyengar S, Skljarevski V, Li L, Bennett R, Collins $\mathrm{H}$ : Duloxetine, a centrally acting analgesic, in the treatment of patients with osteoarthritis knee pain: a 13-week, randomized, placebo-controlled trial. Pain 2009, 146:253-260.

28. Gahimer J, Wernicke J, Yalcin I, Ossanna M, Wulster-Radcliffe M, Viktrup L: A retrospective pooled analysis of duloxetine safety in 23,983 subjects. Curr Med Res Opin 2007, 23:175-184

29. Cymbalta prescribing information. Indianapolis, IN: Eli Lilly and Company; 2011.

30. Dworkin RH, Turk DC, Peirce-Sandner S, Baron R, Bellamy N, Burke LB, Chappell A, Chartier K, Cleeland CS, Costello A, Cowan P, Dimitrova R, Ellenberg S, Farrar JT, French JA, Gilron I, Hertz S, Jadad AR, Jay GW, Kalliomäki J, Katz NP, Kerns RD, Manning DC, McDermott MP, McGrath PJ, Narayana A, Porter L, Quessy S, Rappaport BA, Rauschkolb C, et al: Research design considerations for confirmatory chronic pain clinical trials: IMMPACT recommendations. Pain 2010, 149:177-193.

31. Bellamy N, Buchanan WW, Goldsmith CH, Campbell J, Stitt LW: Validation study of WOMAC: a health status instrument for measuring clinically important patient relevant outcomes to antirheumatic drug therapy in patients with osteoarthritis of the hip or knee. J Rheumatol 1988, 15:1833-1840

32. The Information Centre for Health and Social Care: Prescription cost analysis: England 2009. Leeds: NHS Information Centre for Health and Social Care; 2010.

33. National Institute for Health and Clinical Excellence: Single Technology Appraisal (STA). Specification for manufacturer/sponsor submission of evidence. London: NICE; 2009.

34. Dougados M, LeClaire P, Van der Heijde D, Bloch DA, Bellamy N, Altman RD: A report of the Osteoarthritis Research Society International Standing Committee for clinical trials response criteria initiative. Osteoarthr Cartil 2000, 8:395-403.

35. Moore RA, Moore OA, Derry S, Peloso PM, Gammaitoni AR, Wang H: Responder analysis for pain relief and numbers needed to treat in a meta-analysis of etoricoxib osteoarthritis trials: bridging a gap between clinical trials and clinical practice. Ann Rheum Dis 2010, 69:374-379.

36. Gana TJ, Pascual ML, Fleming RR, Schein JR, Janagap CC, Xiang J, Vorsanger GJ: Extended-release tramadol in the treatment of osteoarthritis: a multicenter, randomized, double-blind, placebo-controlled clinical trial. Curr Med Res Opin 2006, 22:1391-1401.

37. Borenstein M, Hedges LV, Higgins JPT, Rothstein HR: Introduction to Meta-Analysis. 1st edition. West Sussex: Wiley; 2009.

38. Bucher HC, Guyatt GH, Griffith LE, Walter SD: The results of direct and indirect treatment comparisons in meta-analysis of randomized controlled trials. J Clin Epidemiol 1997, 50:683-691.

39. Glenny AM, Altman DG, Song F, Sakarovitch C, Deeks JJ, D'Amico R, Bradburn M, Eastwood AJ: Indirect comparisons of competing interventions. Health Technol Assess 2005, 9:1-134.

40. Song F, Harvey I, Lilford R: Adjusted indirect comparison may be less biased than direct comparison for evaluating new pharmaceutical interventions. J Clin Epidemiol 2008, 61:455-463.

41. Song F, Altman DG, Glenny A-M, Deeks JJ: Validity of indirect comparison for estimating efficacy of competing interventions: empirical evidence from published meta-analyses. BMJ 2003, 326:472

42. Borenstein M, Hedges L, Higgins J, Rothstein H: Comprehensive Meta-Analysis. Biostat: Englewood NJ; 2005.

43. Dias S, Welton NJ, Sutton AJ, Ades AE: NICE DSU Technical Support Document 2: A generalised linear modelling framework for pairwise and network meta-analysis of randomised controlled trials; 2012.

44. Dias S, Sutton AJ, Welton NJ, Ades AE: NICE DSU Technical Support Document 3: Heterogeneity: subgroups, meta- regression, bias and bias-adjustment; 2012.

45. Cooper NJ, Sutton AJ, Morris D, Ades AE, Welton NJ: Addressing betweenstudy heterogeneity and inconsistency in mixed treatment comparisons: Application to stroke prevention treatments in individuals with non-rheumatic atrial fibrillation. Stat Med 2009, 28:1861-1881.

46. Dias S, Welton NJ, Caldwell DM, Ades AE: Checking consistency in mixed treatment comparison meta-analysis. Stat Med 2010, 29:932-944.

47. Lunn DJ, Thomas A, Best N, Spiegelhalter D: WinBUGS - a Bayesian modelling framework: concepts, structure, and extensibility. Stat Comput 2000, 10:325-337.

48. Dickson D, Hosie G, English J: The Primary Care Rheumatology Society OA Knee Study Group: a double-blind, placebo-controlled comparison of hylan G-F 20 against diclofenac in knee osteoarthritis. Clin Res 2001, 4:41-52.

49. Abou-Raya S, Abou-Raya A, Helmii M: Duloxetine for the management of pain in older adults with knee osteoarthritis: randomised placebo-controlled trial. Age Ageing 2012, 41:646-652.

50. Afilalo M, Etropolski MS, Kuperwasser B, Kelly K, Okamoto A, Van Hove I, Steup A, Lange B, Rauschkolb C, Haeussler J: Efficacy and safety of tapentadol extended release compared with oxycodone controlled release for the management of moderate to severe chronic pain related to osteoarthritis of the knee: a randomized, double-blind, placebo- and active-controlled phase III study. Clin Drug Investig 2010, 30:489-505.

51. Baerwald C, Verdecchia P, Duquesroix B, Frayssinet $H$, Ferreira T: Efficacy, safety, and effects on blood pressure of naproxcinod $750 \mathrm{mg}$ twice daily compared with placebo and naproxen $500 \mathrm{mg}$ twice daily in patients with osteoarthritis of the hip: a randomized, double-blind, parallel-group, multicenter study. Arthritis Rheum 2010, 62:3635-3644

52. Bensen WG, Fiechtner JJ, McMillen JI, Zhao WW, Yu SS, Woods EM, Hubbard RC, Isakson PC, Verburg KM, Geis GS: Treatment of osteoarthritis 
with celecoxib, a cyclooxygenase-2 inhibitor: a randomized controlled trial. Mayo Clin Proc 1999, 74:1095-1105.

53. Bingham CO, Sebba Al, Rubin BR, Ruoff GE, Kremer J, Bird S, Smugar SS, Fitzgerald BJ, O'Brien K, Tershakovec AM: Efficacy and safety of etoricoxib $30 \mathrm{mg}$ and celecoxib $200 \mathrm{mg}$ in the treatment of osteoarthritis in two identically designed, randomized, placebo-controlled, non-inferiority studies. Rheumatology (Oxford) 2007, 46:496-507.

54. Boswell DJ, Ostergaard K, Philipson RS, Hodge RA, Blum D, Brown JC, Quessy SN: Evaluation of GW406381 for treatment of osteoarthritis of the knee: two randomized, controlled studies. Medscape J Med 2008, 10:259.

55. Burch F, Fishman R, Messina N, Corser B, Radulescu F, Sarbu A, Craciun-Nicodin MM, Chiriac R, Beaulieu A, Rodrigues J: Others: A comparison of the analgesic efficacy of Tramadol Contramid OAD versus placebo in patients with pain due to osteoarthritis. J Pain Symptom Manage 2007 34:328-338.

56. Clegg DO, Reda DJ, Harris CL, Klein MA, O'Dell JR, Hooper MM, Bradley JD, Bingham CO, Weisman MH, Jackson CG, Lane NE, Cush JJ, Moreland LW, Schumacher HR, Oddis CV, Wolfe F, Molitor JA, Yocum DE, Schnitzer TJ, Furst DE, Sawitzke AD, Shi H, Brandt KD, Moskowitz RW, Williams HJ: Glucosamine, chondroitin sulfate, and the two in combination for painful knee osteoarthritis. N Engl J Med 2006, 354:795-808.

57. DeLemos BP, Xiang J, Benson C, Gana TJ, Pascual ML, Rosanna R, Fleming B: Tramadol hydrochloride extended-release once-daily in the treatment of osteoarthritis of the knee and/or hip: a double-blind, randomized, dose-ranging trial. Am J Ther 2011, 18:216-226.

58. Essex MN, Bhadra P, Sands GH: Efficacy and tolerability of celecoxib versus naproxen in patients with osteoarthritis of the knee: a randomized, double-blind, double-dummy trial. J Int Med Res 2012, 40:1357-1370.

59. Fishman RL, Kistler CJ, Ellerbusch MT, Aparicio RT, Swami SS, Shirley ME, Jain AK, Fortier L, Robertson S, Bouchard S: Efficacy and safety of 12 weeks of osteoarthritic pain therapy with once-daily tramadol (Tramadol Contramid OAD). J Opioid Manag 2007, 3:273.

60. Fleischmann R, Sheldon E, Maldonado-Cocco J, Dutta D, Yu S, Sloan VS: Lumiracoxib is effective in the treatment of osteoarthritis of the knee: a prospective randomized 13-week study versus placebo and celecoxib. Clin Rheumatol 2006, 25:42-53.

61. Fleischmann RM, Caldwell JR, Roth SH, Tesser JR, Olson W, Kamin M: Tramadol for the treatment of joint pain associated with osteoarthritis: a randomized, double-blind, placebo-controlled trial. Curr Ther Res 2001, 62:113-128.

62. Hochberg MC, Fort JG, Svensson O, Hwang C, Sostek M: Fixed-dose combination of enteric-coated naproxen and immediate-release esomeprazole has comparable efficacy to celecoxib for knee osteoarthritis: two randomized trials. Curr Med Res Opin 2011, 27:1243-1253.

63. Kivitz A, Eisen G, Zhao WW, Bevirt T, Recker DP: Randomized placebo-controlled trial comparing efficacy and safety of valdecoxib with naproxen in patients with osteoarthritis. J Fam Pract 2002, 51:530-537.

64. Kivitz AJ, Moskowitz RW, Woods E, Hubbard RC, Verburg KM, Lefkowith JB, Geis GS: Comparative efficacy and safety of celecoxib and naproxen in the treatment of osteoarthritis of the hip. J Int Med Res 2001, 29:467-479.

65. Lehmann R, Brzosko M, Kopsa P, Nischik R, Kreisse A, Thurston H, Litschig S, Sloan VS: Efficacy and tolerability of lumiracoxib $100 \mathrm{mg}$ once daily in knee osteoarthritis: a 13-week, randomized, double-blind study vs. placebo and celecoxib. Curr Med Res Opin 2005, 21:517-526.

66. Leung AT, Malmstrom K, Gallacher AE, Sarembock B, Poor G, Beaulieu A, Castro R, Sanchez M, Detora LM, Ng J: Efficacy and tolerability profile of etoricoxib in patients with osteoarthritis: a randomized, double-blind, placebo and active-comparator controlled 12-week efficacy trial. Curr Med Res Opin 2002, 18:49-58.

67. Markenson JA, Croft J, Zhang PG, Richards P: Treatment of persistent pain associated with osteoarthritis with controlled-release oxycodone tablets in a randomized controlled clinical trial. Clin J Pain 2005, 21:524.

68. Puopolo A, Boice JA, Fidelholtz JL, Littlejohn TW, Miranda P, Berrocal A, Ko A, Cichanowitz N, Reicin AS: A randomized placebo-controlled trial comparing the efficacy of etoricoxib $30 \mathrm{mg}$ and ibuprofen $2400 \mathrm{mg}$ for the treatment of patients with osteoarthritis. Osteoarthr Cartil 2007, 15:1348-1356

69. Rauck R, Rapoport R, Thipphawong J: Results of a double-blind, placebo-controlled, fixed-dose assessment of once-daily OROS ${ }^{\circledR}$ hydromorphone ER in patients with moderate to severe pain associated with chronic osteoarthritis. Pain Pract 2013, 13:18-29.
70. Schnitzer TJ, Dattani ID, Seriolo B, Schneider H, Moore A, Tseng L, Sallstig P, Rebuli R, Maxwell T: A 13-week, multicenter, randomized, double-blind study of lumiracoxib in hip osteoarthritis. Clin Rheumato/ 2011, 30:1433-1446.

71. Schnitzer TJ, Hochberg MC, Marrero CE, Duquesroix B, Frayssinet $H$, Beekman M: Efficacy and safety of naproxcinod in patients with osteoarthritis of the knee: a 53-week prospective randomized multicenter study. Semin Arthritis Rheum 2011, 40:285-297.

72. Schnitzer TJ, Kivitz A, Frayssinet H, Duquesroix B: Efficacy and safety of naproxcinod in the treatment of patients with osteoarthritis of the knee: a 13-week prospective, randomized, multicenter study. Osteoarthr Cartil 2010, 18:629-639.

73. Sheldon E, Beaulieu A, Paster Z, Dutta D, Yu S, Sloan VS: Efficacy and tolerability of lumiracoxib in the treatment of osteoarthritis of the knee: a 13-week, randomized, double-blind comparison with celecoxib and placebo. Clin Ther 2005, 27:64-77.

74. Sowers JR, White WB, Pitt B, Whelton A, Simon LS, Winer N, Kivitz A, van Ingen $\mathrm{H}$, Brabant T, Fort JG: The effects of cyclooxygenase- 2 inhibitors in patients with hypertension, osteoarthritis, and type 2 diabetes mellitus. Arch Intern Med 2005, 165:161-168.

75. Tannenbaum H, Berenbaum F, Reginster J-Y, Zacher J, Robinson J, Poor G, Bliddal $H$, Uebelhart D, Adami S, Navarro F, Lee A, Moore A, Gimona A: Lumiracoxib is effective in the treatment of osteoarthritis of the knee: a 13 week, randomised, double blind study versus placebo and celecoxib. Ann Rheum Dis 2004, 63:1419-1426.

76. Vojtaššák J, Vojtaššák J, Jacobs A, Rynn L, Waechter S, Richarz U: A phase iiib, multicentre, randomised, parallel-group, placebo-controlled, double-blind study to investigate the efficacy and safety of oros hydromorphone in subjects with moderate-to-severe chronic pain induced by osteoarthritis of the hip or the knee. Pain Res Treat 2011, 2011:239501.

77. Wiesenhutter CW, Boice JA, Ko A, Sheldon EA, Murphy FT, Wittmer BA, Aversano ML, Reicin AS: Evaluation of the comparative efficacy of etoricoxib and ibuprofen for treatment of patients with osteoarthritis: a randomized, double-blind, placebo-controlled trial. Mayo Clin Proc 2005, 80:470-479.

78. Higgins J, Thompson SG: Quantifying heterogeneity in a meta-analysis. Stat Med 2002, 21:1539-1558.

79. Higgins JPT, Green S: (editors) Cochrane Handbook for Systematic Reviews of Interventions. Version 5.1.0. Wiley Online Library; 2011 www.cochrane-handbook.org.

80. Spiegelhalter D, Best N, Carlin B, Van Der Linde A: Bayesian measures of model complexity and fit (with discussion). J R Stat Soc 2002, 64:583-616. Series B.

81. Corrigan R, Derry S, Wiffen PJ, Moore RA: Clonazepam for neuropathic pain and fibromyalgia in adults. Cochrane Database Syst Rev 2012(5), CD009486. DOI: 10.1002/14651858.CD009486.pub2.

82. National Collaborating Centre for Chronic Conditions: Osteoarthritis: National Clinical Guideline for Care and Management in Adults. Appendix D. London: Royal College of Physicians; 2008.

83. Choy E, Marshall D, Gabriel ZL, Mitchell SA: Gylee E. A systematic review and mixed treatment comparison of the efficacy of pharmacological treatments for fibromyalgia. Seminars in Arthritis and Rheumatism: Dakin HA; 2011.

84. Quilici S, Chancellor J, Löthgren M, Simon D, Said G, Le TK, Garcia-Cebrian A, Monz B: Meta-analysis of duloxetine vs. pregabalin and gabapentin in the treatment of diabetic peripheral neuropathic pain. BMC Neurol 2009, 9:6.

85. Trijau S, Avouac J, Escalas C, Gossec L, Dougados M: Influence of flare design on symptomatic efficacy of non-steroidal anti-inflammatory drugs in osteoarthritis: a meta-analysis of randomized placebo-controlled trials. Osteoarthr Cartil 2010, 18:1012-1018.

86. Morrison A, Polisena J, Husereau D, Moulton K, Clark M, Fiander M, MierzwinskiUrban M, Clifford T, Hutton B, Rabb D: The effect of English-language restriction on systematic review-based meta-analyses: a systematic review of empirical studies. Int J Technol Assess Health Care 2012, 28:138-144.

87. Etropolski M, Kelly K, Okamoto A, Rauschkolb C: Comparable efficacy and superior gastrointestinal tolerability (nausea, vomiting, constipation) of tapentadol compared with oxycodone hydrochloride. Adv Ther 2011 28:401-417

doi:10.1186/1471-2474-15-76

Cite this article as: Myers et al:: The efficacy of duloxetine, non-steroidal anti-inflammatory drugs, and opioids in osteoarthritis: a systematic literature review and meta-analysis. BMC Musculoskeletal Disorders 2014 15:76. 